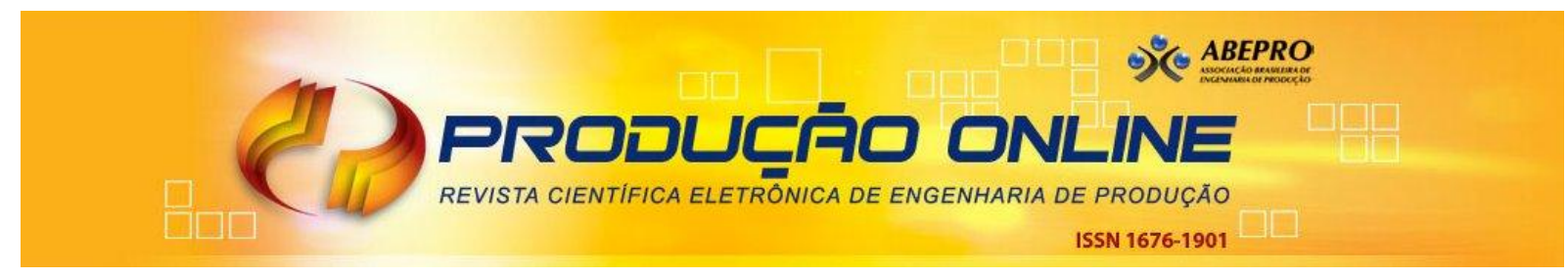

\title{
GESTÃO AMBIENTAL NO SETOR SUCROENERGÉTICO: UMA ANÁLISE COMPARATIVA
}

\section{ENVIRONMENTAL MANAGEMENT IN SUGAR-ENERGY SECTOR: A COMPARATIVE ANALYSIS}

\author{
Andréia Marize Rodrigues* Email: andreiamarize@fcav.unesp.br \\ Marcelo Giroto Rebelato* Email: mgiroto@fcav.unesp.br \\ Renata Bombonato Strini Paixão* Email: renata.strini@gmail.com \\ Caio Henrique Zeviani* Email: caio zeviani@hotmail.com \\ * Universidade Estadual Paulista (UNESP), Jaboticabal, SP
}

Resumo: Com a ascensão da variável ambiental no ambiente dos negócios, as empresas passaram a dispensar maior atenção a estratégias e a práticas focadas no uso racional dos recursos naturais e na minimização dos impactos ambientais causados por suas operações produtivas. Muitos setores produtivos se destacaram nas reflexões sobre produção e meio ambiente, como é o caso do setor sucroenergético, que se constitui em um setor com uma atividade industrial altamente demandadora de recursos naturais, quer seja como fontes de insumos quanto como depositárias de resíduos da produção. Desta maneira, o objetivo do presente artigo consiste na análise comparativa das práticas ambientais de duas usinas sucroenergéticas, tanto sob o ponto de vista de suas estratégicas quanto relativamente à adequação da destinação de resíduos gerados pela área industrial. Foi possível concluir que, apesar de muitas práticas adotadas pelas empresas serem análogas, uma das usinas estudadas possui desempenho ambiental diferenciado, dada à maior atenção dispensada à execução de suas práticas ambientais e, sobretudo, na inclusão da variável ambiental em suas estratégias.

Palavras-chave: Gestão Ambiental. Práticas Ambientais. Setor Sucroenergético. Estratégia. Resíduo.

Abstract: With the rise of the environmental variable in the business environment, companies started to give greater attention to strategies and practices focused on the rational use of natural resources and minimize the environmental impacts of their business operations. Many productive sectors stood out in the reflections on production and the environment, as is the case of the sugar energy industry, which constitutes a sector with a highly demanding industrial activity of natural resources, whether as sources of inputs as depositories of waste production. Thus, the aim of this paper is a comparative analysis of environmental practices of two sugar energy plants, both from the point of view of their operational strategy and regarding the suitability of the disposal of waste generated by the industrial area. It was concluded that, although many practices adopted by businesses are analogous, one of the studied plants have distinctive environmental performance, because of the increased attention given to the implementation of environmental practices and especially the inclusion of the environmental variable in their strategies.

Keywords: Environmental Management. Environmental Practices. Sugar Energy Industry. Strategy. Waste. 


\section{INTRODUÇÃO}

Acidentes ambientais e conferências internacionais sobre meio ambiente ocorridos nas últimas décadas contribuíram para 0 aprimoramento das regulamentações ambientais sobre as empresas e para o aumento das pressões da sociedade por produtos e processos que não agridam o meio ambiente, sendo a sustentabilidade das operações considerada atualmente como uma responsabilidade das organizações (DONAIRE, 1999; CAMPOS e MELO, 2008).

É possível notar nas empresas uma crescente preocupação com os danos ambientais provenientes de suas operações, passando estes a serem considerados nas decisões empresariais. A inclusão da variável ambiental nas organizações de forma estratégica é cada vez mais observada, seja por pressões legais e sociais ou por representar oportunidades empresariais (ZEVIANI et al., 2013).

Neste contexto, muitas empresas passaram a dispensar maior atenção a técnicas e a processos produtivos focados no uso racional dos recursos naturais e geradores de menor impacto ambiental, havendo a busca por configurações de modelos de gestão ambiental visando controle de suas ações sobre o ambiente. O meio ambiente passou a ser considerado nas decisões das organizações, tornandose importante elemento na elaboração de suas estratégias (RODRIGUES et al., 2013; SANCHES, 2000).

Muitos setores produtivos se destacaram nas reflexões sobre produção e meio ambiente. Este é o caso do setor sucroenergético, no qual as usinas produtoras de açúcar, álcool e energia sempre lidaram com problemas ambientais resultados de seus processos produtivos. Isto porque este setor possui uma atividade industrial demandadora dos recursos naturais, quer seja como fontes de insumos quanto como depositárias de resíduos da produção. Para este setor, as operações produtivas relacionadas ao processamento da cana de açúcar causam impactos significativos ao meio ambiente, como a utilização intensiva de água e a geração de resíduos potencialmente poluidores, caso da vinhaça e da torta de filtro (PIACENTE, 2005; REBELATO et al., 2012). Por estas características, o setor é atualmente regido por uma série de legislações com o propósito de regular as 
atividades produtivas visando à prevenção e à minimização dos impactos ambientais de suas operações (OLIVEIRA et al., 2009).

Entretanto, para este setor esse cenário vem se modificando pela adoção de práticas estratégicas para a conscientização sobre as atitudes da empresa frente a esta nova realidade e pela adequação de técnicas de produção visando ao reaproveitamento de resíduos e à redução de impactos ambientais das atividades.

Mediante este contexto, tornam-se interessantes pesquisas que tenham por intuito a apuração de como as empresas deste setor vêm conduzindo suas ações ambientais e a relação destas ações com a estrutura estratégica das empresas. Além disso, ressalta-se a relevância de estudos que revelem a adequação da destinação dos resíduos e subprodutos provenientes de suas operações industriais. Desta maneira, o objetivo do presente artigo consiste na análise comparativa das práticas ambientais tanto estratégicas quanto concernentes à adequação da destinação de resíduos do setor industrial de duas usinas sucroenergéticas.

Para tanto, este trabalho se divide em cinco tópicos, a contar com esta introdução. Nos tópicos dois e três são brevemente expostos os conceitos relacionados à temática, quais sejam Gestão Ambiental e a questão ambiental no setor sucroenergético. No quarto tópico é realizada a explanação comparativa dos dados coletados em ambas as usinas estudadas. Por fim, o tópico cinco traça as considerações finais do trabalho.

\section{METODOLOGIA}

O estudo trata-se de uma pesquisa descritiva e qualitativa com a interpretação e análise de dados utilizando descrições e narrativas de acordo com o ambiente em questão, baseada no método de estudo de caso.

Para a realização deste trabalho, optou-se pela sua divisão em seis etapas, a saber:

- Etapa 1: Levantamento bibliográfico de assuntos relacionados a Gestão Ambiental, Sistemas de Gestão Ambiental e certificação ambiental;

- Etapa 2: Mapeamento do fluxo produtivo de plantas industriais processadoras de cana de açúcar com a finalidade de levantar os principais resíduos e 
subprodutos gerados nas etapas produtivas e sua correlação com a legislação pertinente;

- Etapa 3: construção de um roteiro semiestruturado de pesquisa para auxílio na coleta dos dados pretendidos. Este roteiro foi dividido em duas partes:

i. Avaliação das estratégias ambientais, abordando os seguintes assuntos: estratégias ambientais; certificações ambientais; educação e projetos ambientais; divulgação das práticas ambientais; balanço das práticas ambientais; e motivação e resultados obtidos com os investimentos em práticas ambientais;

ii. Avaliação da adequação da destinação de resíduos e subprodutos gerados durante as etapas industriais da produção sucroenergética.

- Etapa 4: seleção das empresas participantes da pesquisa. Foram selecionadas duas empresas pelo caráter comparativo do trabalho. As usinas foram selecionadas a partir do critério conveniência e doravante são chamadas de usinas A e B;

- Etapa 5: realização das entrevistas, conduzidas pessoalmente com o diretor industrial de cada empresa;

- Etapa 6: Análise e descrição dos dados coletados.

\section{GESTÃO AMBIENTAL: DEFINIÇÃO E CARACTERÍSTICAS}

A Gestão Ambiental pode ser definida como uma série de medidas e procedimentos que visam à redução e ao controle dos impactos introduzidos por um empreendimento sobre o meio ambiente (ARAÚJO, 2001; MAIMOM, 1996; DIAS, 2006).

Cada empresa possui uma postura com relação a seu gerenciamento ambiental. Neste sentido, Barbieri (2007) propõe três diferentes abordagens relacionadas à Gestão Ambiental:

- Controle da poluição: postura reativa visando ao cumprimento da legislação e respostas às pressões da comunidade; 
- Prevenção da poluição: postura tanto proativa quanto reativa, apresentando ações corretivas e preventivas. A preocupação básica centra-se no uso eficiente dos insumos;

- Estratégica: postura proativa cuja preocupação básica centra-se na competitividade. Envolvimento permanente e sistemático da alta administração.

No mesmo sentido, Hunt e Auster (1990) abordam a Gestão Ambiental através de uma classificação em cinco estágios. O primeiro estágio é determinado pela ausência ou limitação de programas de ambientais. O segundo estágio é formado por um apoio centralizado da organização, que auxilia na resolução das crises ambientais. No terceiro estágio a organização considera somente relevante a prevenção de acidentes e para isso existe um departamento ambiental formado por especialistas, porém sem poderes para fazer mudanças efetivas. No quarto estágio os problemas ambientais já são gerenciados através de departamentos com experiência, financiamento e autoridade, onde são avaliados riscos ambientais e desenvolvido o treinamento em educação ambiental. Por fim, no quinto nível as questões ambientais passam a ser englobadas às metas, políticas e estratégias da empresa, considerando o impacto ambiental de seus processos e produtos.

$\mathrm{Na}$ adoção de qualquer modelo de Gestão Ambiental é necessário dispor de ferramentas ou instrumentos para alcançar as metas ambientais. Nessa direção, emerge a demanda de empresas em busca de um Sistema de Gestão Ambiental (SGA) que possa ser aplicado no gerenciamento e no controle das ações das empresas sobre o ambiente, visando minimizar problemas ambientais advindos do sistema produtivo (BARBIERI, 2007).

O SGA pode ser conceituado como uma parte de um sistema de gestão que compreende a estrutura funcional, responsabilidades, práticas, processos, procedimentos e recursos para a realização e construção da política ambiental da empresa. Para sua implantação, a empresa deve seguir etapas como construir juntamente com os funcionários a conscientização ambiental; efetuar uma análise ambiental preliminar de todas as atividades da empresa; definir a política ambiental que deverá ser adotada; e elaborar um programa ambiental que norteie ações dentro do planejamento empresarial (ARAÚJO, 2001). 
Os métodos utilizados para a efetivação do SGA são inúmeros e diferentes entre si; porém, todos visam ao menor impacto no ambiente e à vantagem competitiva em relação aos concorrentes. Dentre estes se encontram as normas da série ISO 14000, que se propõem a servir como um guia para que as empresas possam criar, documentar, implantar e manter um sistema efetivo de Gestão Ambiental (CAGNIN, 2000).

O objetivo dessas normas é fornecer às organizações elementos de um SGA eficaz, capaz de ser integrado a outros aspectos da gestão, auxiliando no alcance dos objetivos ambientais. Desta maneira, é esperado que as normas da ISO 14000 se apliquem a todos os tipos e portes de organizações adequando-se em diferentes condições geográficas, culturais e sociais (ABNT, 2004).

\subsection{O setor sucroenergético e a questão ambiental}

De acordo com Rossetto (2008), na década de 1970 a indústria sucroenergética apresentava um elevado potencial poluidor. Nas décadas seguintes, os movimentos ambientalistas começam a tomar força e, impulsionadas pelo novo conceito de desenvolvimento sustentável, as usinas sucroenergéticas passaram a uma nova atitude frente aos problemas ambientais. A imagem do setor de degradador do ambiente foi migrando para o uso de técnicas mais sustentáveis, com a utilização de novas tecnologias, o atendimento a políticas públicas e uma nova consciência ambiental.

\subsection{Certificações ambientais do setor sucroenergético}

As certificações ambientais passaram a constituir em uma das formas adotadas pelas empresas do setor para atestar a adoção de parâmetros sustentáveis, seja para o atendimento a legislações ambientais ou para atestar práticas ambientais voluntárias (FERRAZ, 2007). Além da ISO 14001, muito utilizada para atestar um Sistema de Gestão Ambiental nas organizações, a seguir são apresentadas as principais certificações ambientais encontradas no setor. 
a) Certificação Mesa Redonda Biocombustíveis Sustentáveis (RSB): certificado internacional desenvolvido para garantir a sustentabilidade dos biocombustíveis medida por toda cadeia produtiva;

b) Bonsucro: surgiu através da Better Sugarcane Initiative, uma associação dedicada a reduzir os impactos ambientais e sociais da produção de cana de açúcar, sendo exclusivamente voltada ao setor sucroenergético;

c) Greenergy Bioethanol Sustainability Programme: selo validado por toda Comunidade Europeia, que atesta uma produção de etanol anidro da forma sustentável além de maximizar economias de emissão de gases de efeito estufa;

d) Protocolo Agroambiental: desenvolvido pelo Governo do Estado de São Paulo, pelas Secretarias de Estado do Meio Ambiente e de Agricultura e Abastecimento e pela União da Indústria Sucroalcooleira (UNICA), pertence ao Projeto Etanol Verde, que estimula ações de sustentabilidade na cadeia produtiva de açúcar e bioenergia;

e) Certificação de Projetos de MDL: decorrentes dos projetos atestados pelo Conselho Executivo de MDL, que comprovam a redução dos gases do efeito estufa na atmosfera ou a capacidade de capturá-los;

f) Environmental Protection Agency (EPA): certificado norte-americano, necessário para exportar etanol para aquele país;

g) International Sustainability and Carbon Certification (ISCC): se refere à biomassa e à bioenergia de acordo com os parâmetros obrigatórios para todos os países-membros da União Europeia;

h) Roundtable on Sustainable Biofuels (RSB): iniciativa internacional de partes interessadas, criada para garantir a sustentabilidade dos biocombustíveis mediante o entendimento e a aceitação da RSB às partes interessadas e aos clientes;

i) Global Reporting Initiative (GRI): utilizada como metodologia para a elaboração de Relatórios de Sustentabilidade; padrão internacional de relato que engloba um conjunto de indicadores acerca das práticas, da gestão e do desempenho nos âmbitos econômico, social e ambiental. 


\subsection{Resíduos e subprodutos da produção sucroenergética}

A Figura 1 apresenta simplificadamente os processos sucroenergéticos, apresentando-se na cor preta os processos produtivos, em azul os resíduos gerados e em vermelho os subprodutos. Conceitua-se aqui como resíduo o que é produzido e que não pode ser aproveitado economicamente. Já para poder ser considerado como subproduto, segundo Fipa (2007), a substância ou material deve atender aos seguintes requisitos: a) existir uma utilização futura para este; b) poder ser utilizado sem sofrer alterações; c) fazer parte integrante de um processo de produção contínuo.

Estes resíduos/subprodutos possuem composições que, em geral, impossibilitam sua descarga no meio ambiente, exigindo tratamentos para viabilizarem sua reutilização ou descarte sem causar impactos ambientais. Todos possuem legislações e normas que regulamentam sua aplicação e tratamento além de possuírem destinações ambientalmente recomendáveis.

Pelo levantamento realizado foi possível identificar que na industrialização da cana de açúcar podem ser gerados 23 resíduos/subprodutos principais, cada qual explicado na sequência quanto à etapa produtiva em que é gerado, sua composição, a legislação pertinente e as possíveis destinações. 
Figura 1- Fluxograma simplificado da produção industrial sucroenegética com destaque para os resíduos e subprodutos gerados

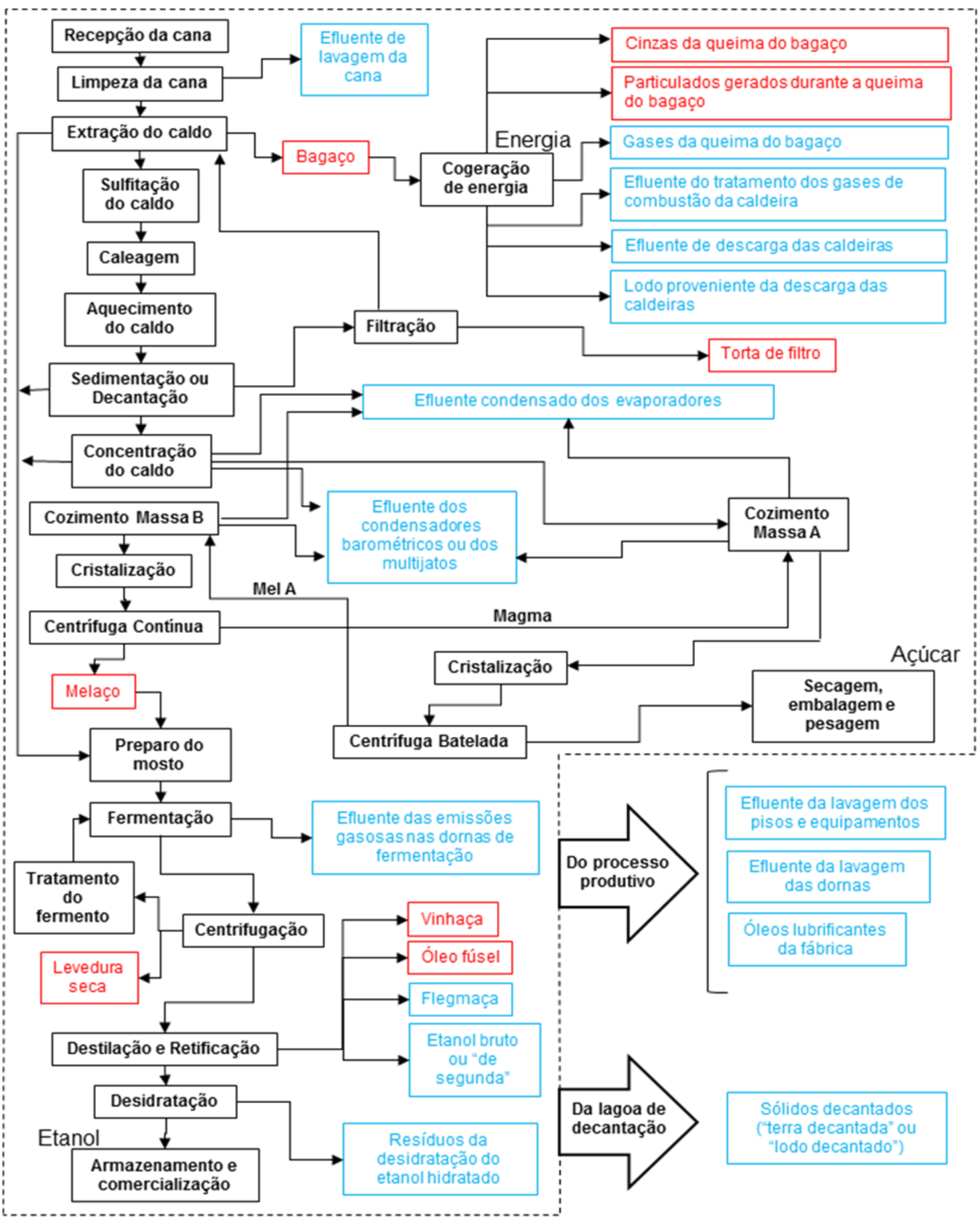

Fonte: Elaboração própria.

Revista Produção Online, Florianópolis, SC, v.14, n. 4, p. 1481-1510, out./dez. 2014. 
As etapas industriais da produção sucroenergética iniciam-se com a recepção da cana, cuja limpeza é realizada a partir da lavagem com água ou a seco. O processo de lavagem com água gera o chamado efluente de lavagem da cana, cuja composição se constitui de água, terra e palha. Este resíduo se caracteriza por apresentar alta demanda bioquímica de oxigênio (DBO) - entre 200 e 1200 mg/l - e é regido pela norma CETESB D3.591. Dentre as destinações mais usuais estão: fertirrigação (irrigação da cana de açúcar), recirculação (no processo produtivo), tratamento e lançamento em corpos d'água após tratamento em lagoas de decantação e de estabilização.

Já o bagaço se constitui em um subproduto da etapa produtiva de extração do caldo, sendo composto basicamente de fibras e de água. A legislação pertinente a este resíduo se constitui da Lei $n^{\circ} 12.305$ de 2010 e da resolução CONAMA nº 313/2002. A sua destinação mais comum é a cogeração de energia elétrica, podendo ainda ser destinado à lavoura como adubo e à produção de ração animal, de aglomerados e de celulose.

Da etapa de cogeração de energia elétrica são originados dois subprodutos e quatro resíduos. Dentre os subprodutos estão as chamadas cinzas da queima do bagaço, cuja composição se faz exclusivamente por óxidos. Como legislações pertinentes a este resíduo estão a Lei n`12.305 de 2010 e a resolução CONAMA n 313/2002. Quanto às destinações, estas podem ser aplicação no campo (adubação), área de aterro, produção de cimento e compostagem com minerais.

Os particulados gerados durante a queima do bagaço são subprodutos constituídos por bagacilhos queimados e semiqueimados durante a combustão do bagaço. Sua aplicação normalmente é na lavoura como componente do processo de adubação. As legislações pertinentes ao resíduo são as resoluções CONAMA $n^{\circ}$ 3/1990, n० 382/2006 e n० 436/2011.

Os gases da queima do bagaço se constituem em um dos quatro resíduos da etapa de cogeração, sendo compostos basicamente por metano, ozônio, dióxido de carbono, dióxido de enxofre, monóxido de carbono, óxido nitroso e óxido de nitrogênio. Estes gases são regidos pelas mesmas legislações dos particulados da queima do bagaço, sendo normalmente lançados no ambiente. 
O segundo resíduos resultado da cogeração de energia é denominado de efluente do tratamento dos gases de combustão da caldeira e possui DBO entre 100 e $300 \mathrm{mg} / \mathrm{l}$ e alta temperatura (por volta de $80^{\circ} \mathrm{C}$ ). As resoluções CONAMA $n^{\circ}$ 357/2005, n 410/2009 e n 430/2011 regem este resíduo e sua destinação, após tratamento em tanque de sedimentação, é a recirculação à etapa de lavagem da cana.

O efluente de descarga das caldeiras se constitui no terceiro resíduo proveniente da etapa de cogeração, possui DBO baixa e sua destinação mais comum é a sua incorporação à caixa receptora de vinhaça para fertirrigação. Este efluente é regido pela DIRETORIA CETESB n 195-2005-E.

Já o lodo proveniente da descarga das caldeiras, quarto resíduo da cogeração, é composto por sílica, cálcio e magnésio. Regido pela Lei $\mathrm{n}^{\circ}$ $12.305 / 2010$ e pela resolução CONAMA $n^{\circ} 313 / 2002$, possui como principais destinações a aplicação na lavoura e área de aterro.

$\mathrm{Na}$ etapa de filtração do caldo extraído é gerado o subproduto denominado torta de filtro. Este subproduto é composto de doze elementos, tais como matéria orgânica, nitrogênio, fósforo e potássio. Por conter quantidades significativas de cálcio e fósforo, é normalmente utilizado na aplicação na lavoura, podendo ou não passar por processo de compostagem. Quanto à legislação pertinente tem-se a Lei $n^{\circ}$ 12.305/2010 e a resolução CONAMA n॰ 313/2002.

Das etapas de concentração do caldo e cozimento é gerado o chamado efluente condensado dos evaporadores. Este resíduo se caracteriza por apresentar DBO na faixa de $150 \mathrm{mg} / \mathrm{l}$, resíduo total de $140 \mathrm{mg} / \mathrm{l}$ e pH 7,2 e é regido pelas resoluções CONAMA $n^{\circ} 357 / 2005, n^{\circ} 410 / 2009$ e $n^{\circ} 430 / 2011$. Pode ser reutilizado em caldeiras de baixa pressão e no processo industrial (a depender do nível de contaminação) ou, ainda, para a limpeza de pisos e equipamentos.

O efluente dos condensadores barométricos ou dos multijatos possui sua geração nas etapas de concentração do caldo e cozimento da massa B. Possui baixa DBO (10 a $40 \mathrm{mg} / \mathrm{l}), \mathrm{pH} 6,9$ e média temperatura (por volta de $45^{\circ} \mathrm{C}$ ). A legislação pertinente a este resíduo são as resoluções CONAMA n³57/2005, n 410/2009 e n 430/2011. São duas as destinações mais comuns: recirculação ao 
processo após tratamento (resfriamento) ou lançamento em corpos d’água, respeitando os padrões de qualidade do corpo receptor.

O subproduto melaço, composto por frutose, sacarose e maltose, é regido pela Lei Estadual n 12.300/2006 e pela instrução normativa IBAMA n 6/2001 e possui como destinações a produção do etanol, o uso como fertilizante ou a composição de ração animal.

Proveniente da etapa de fermentação, o efluente das emissões gasosas nas dornas de fermentação é composto por gás carbônico e regido pela Lei $n^{\circ}$ 12.305/2010. Apesar de seu valor comercial, este resíduo é normalmente liberado no ambiente.

Da etapa de centrifugação do fermento tem-se a levedura seca. Composta por proteínas, cálcio, fósforo, magnésio, sódio, cloro e enxofre, este subproduto, regido pela Lei $n^{\circ} 12.305 / 2010$ e pela resolução CONAMA n 313/2002, destina-se normalmente à alimentação animal, à alimentação humana e à lavoura (fertilização).

Após a centrifugação, a etapa de destilação e retificação gera dois subprodutos (vinhaça e óleo fúsel) e dois resíduos (flegmaça e etanol bruto). A vinhaça é acompanhada pelas portarias CETESB P4.231 e CTSA 1/2005 e possui em sua composição nitrogênio, fósforo, potássio, óxidos, sulfatos, matéria orgânica, possuindo ainda altas DBO e DQO (demanda química de oxigênio). Via de regra, é utilizada na fertirrigação podendo, ainda, sofrer destinações como produção de biogás, de ração animal, de fungos e de material para construção, podendo ainda ser incinerada.

O subproduto óleo fúsel, composto pelos alcoóis isoamílico, isobutílico, namílico, isopropanol, furfural e ácidos graxos, encontra sua destinação mais comum a utilização como fixador para perfumes, preparo de sabores artificiais ou aromatizantes. Quanto à legislação concernente a este material estão a Lei $n^{\circ}$ $12.305 / 2010$ e a resolução CONAMA n 313/2002.

O flegmaça, que se constitui em uma água com traços de óleo fúsel, pode ser adicionado à vinhaça ou a águas residuárias e, ainda, ser aproveitado para a lavagem de dornas de fermentação e de trocadores de calor. Legislação pertinente ao resíduo: Lei n 12.305/2010 e resolução CONAMA n³13/2002. 
Já o etanol bruto, também chamado de etanol "de segunda", possui em sua composição ácidos, aldeídos e ésteres. Este resíduo é regido pela mesma legislação do flegmaça e possui como destinações retorno à dorna volante (processo produtivo) e agregação ao bagaço para aumentar seu poder calorífico.

Provenientes da etapa de desidratação do etanol, os chamados resíduos da desidratação do etanol hidratado (resina zeolítica) são normalmente destinados a aterros sanitários acompanhado de CADRI (Certificado de Movimentação de Resíduos de Interesse Ambiental). Possui em sua composição alumínio, sílica, ácidos, aldeídos e ésteres. É regido pela Lei n 12.305/2010.

Três resíduos ainda são gerados ao longo do processo produtivo. O primeiro deles denomina-se efluente da lavagem dos pisos e equipamentos. Possui $\mathrm{pH}$ bastante variável e DBO entre 200 e $2.000 \mathrm{mg} / \mathrm{l}$. É controlado pela DIRETORIA CETESB n 195/2005. Quanto à destinação, a mais comum se constitui na fertirrigação, juntamente com a vinhaça, após tratamento em caixas separadoras de óleo. Já o chamado efluente da lavagem das dornas possui efeito poluidor semelhante à vinhaça, embora mais diluído. Desta maneira, sua destinação normalmente acompanha a destinação dada à vinhaça, qual seja, a fertirrigação. $A$ legislação pertinente são as resoluções CONAMA n 357/2005, n 410/2009 e n 430/2011. O terceiro resíduo ainda gerado ao longo do processo produtivo são os chamados óleos lubrificantes da fábrica. Compostos basicamente por ácidos orgânicos, cetonas, resinas lacas e metais, este resíduo é regido pela resolução CONAMA $n^{\circ} 362 / 2005$ e Portarias ANP $n^{\circ} 125$ e $n^{\circ} 126$ e são normalmente comercializados com empresas que se prestam à recuperação de óleos.

Finalmente, estão os sólidos decantados. Regidos pela Lei $n^{\circ}$ 12.305/2010 possuem em sua composição componentes como sílica, fósforo, nitrogênio, potássio, entre outros, e altas DBO e DQO. A destinação normalmente depende da análise do material: quando sem resíduos de óleo seguem à lavoura (adubação) e se detectados resíduos de óleo devem seguir com CADRI a empresas de reciclagem. 


\section{RESULTADOS E DISCUSSÕES}

Neste tópico são expostos os resultados da análise comparativa de duas usinas do setor sucroenergético no âmbito das questões ambientais que as envolvem. As empresas estudadas são analisadas com relação às práticas ambientais adotadas, estando esta discussão dividida em duas partes: a) avaliação das estratégias ambientais; b) avaliação da adequação da destinação de resíduos e sobprodutos.

\subsection{Avaliação das estratégias ambientais}

São aqui analisados os assuntos abordados na primeira parte da pesquisa (Parte I), quais sejam: estratégias ambientais, certificações ambientais, educação e projetos ambientais, divulgação das práticas ambientais, balanço das práticas ambientais, e motivações e resultados dos investimentos ambientais.

\subsubsection{Estratégias ambientais adotadas}

A empresa A, quando da definição de seu planejamento estratégico, leva em consideração a questão da preservação do ambiente, procurando realizar um número maior de projetos ambientais do que as obrigações da legislação ambiental. A empresa busca por tecnologias que minimizem a quantidade de resíduos emitidos e possui o cuidado de cumprir as metas estabelecidas para seus projetos ambientais. Como essa usina discorda da suficiência do cumprimento apenas da legislação vigente para a preservação ambiental, a empresa tem investido em melhorias em processos, tecnologias e iniciativas para melhorar também sua eficiência operacional.

A usina B, por sua vez, entende que o cumprimento da legislação ambiental seja suficiente para proteção do meio ambiente. Este fato foi justificado pela severidade das regulamentações em alguns pontos que envolvem o processo produtivo do setor. A usina alega que estas regulamentações se mostram como parte da motivação da empresa em encontrar melhores tecnologias e inovações 
para cumpri-las. Porém, a empresa alegou estar ciente da necessidade de se buscar por mais práticas sustentáveis, principalmente pelas vantagens produtivas e econômicas por elas geradas.

Ocorreram mudanças no planejamento estratégico da usina $A$ devido às questões ambientais, que podem ser percebidas em sua missão, visão e valores. $A$ partir de 2010, houve a reestruturação estratégica derivada do conceito de desenvolvimento sustentável, sendo possível conceber a organização por meio da sua gestão da sustentabilidade. A partir da valorização da variável ambiental a empresa alega ter alcançado a oportunidade de realização de novos negócios, de reduzir custos operacionais e de aumentar a eficiência das suas operações. Quanto à usina $\mathrm{B}$, não foi possível identificar a mesma inclusão da variável ambiental na definição de suas estratégias. Desta forma, constatou-se pela pesquisa que a empresa aborda a questão apenas a partir da adequação de práticas ambientais às suas estratégias, como forma de alcançar melhor desempenho ambiental para cumprimento de eventuais necessidades regulamentadoras.

A empresa A possui grupos de trabalho que representam sua chamada Gestão da Sustentabilidade através de um Assessor de Tecnologia Ambiental e dos Assistentes de Meio Ambiente, que possuem como função integrar e coordenar ações de cunho ambiental além de fiscalizar o cumprimento da política ambiental. A empresa $B$ conta com um departamento ambiental em sua estrutura organizacional para poder centralizar e dar suporte às questões ambientais.

Quanto ao Sistema de Gestão Ambiental, somente a usina A alegou dispor dessa sistematização formalizada, demonstrando seu empenho em promover sua eficiência ambiental atribuindo responsabilidades, processos e objetivos gerais a serem alcançados. A usina B aplica técnicas no gerenciamento e no controle das ações sobre $\mathrm{O}$ ambiente, visando minimizar problemas ambientais advindos do sistema produtivo, mas não as atestou conforme algum referencial.

Perante a postura da empresa $A$ frente à Gestão Ambiental, a abordagem estratégica, proposta Barbieri (2007), consiste na classificação que mais se enquadra no seu grau de envolvimento com as questões ambientais. A empresa leva a cabo suas estratégias ambientais além de repassar a toda organização as responsabilidades ambientais. Já a usina B, por não contemplar a variável ambiental 
em seu planejamento estratégico e por apresentar uma postura reativa frente aos impactos ambientais, se enquadra no estágio da abordagem da prevenção da poluição.

De acordo com a classificação proposta por Hunt e Auster (1990), a empresa A pode se enquadrar no quinto estágio, uma vez que as questões ambientais estão englobadas em metas e práticas disseminadas por toda organização e há educação para os seus integrantes nesse âmbito. No entanto, a empresa B se enquadra no quarto estágio por já dispor de um departamento ambiental formalizado e comandado por especialistas e por investir na educação ambiental.

\subsubsection{Certificações Ambientais}

No domínio ambiental, as certificações da usina A são:

- Greenergy Bioethanol Sustainability Programme;

- Protocolo Agroambiental;

- Environmental Protection Agency (EPA);

- Atestado da empresa Shell como consequência do selo da Greenergy. Já a usina B é certificada apenas no Protocolo Agroambiental.

Ambas as usinas não dispõem dos Sistemas de Gestão Ambiental mais comuns nas empresas do setor, como o caso da ISO 14000 e do Bonsucro. A empresa A destacou que, apesar de não estar certificada pela ISO 14000, seu SGA funciona plenamente, além de ser formalizado com quesitos semelhantes aos da norma. Quanto à certificação Bonsucro, as empresas alegaram que esta certificação se constitui em uma meta, sendo que a usina $A$ já se encontra em fase de adequação para as próximas safras.

\subsubsection{Educação e Projetos Ambientais}

Questionadas a respeito dos projetos que incentivam a busca por novas soluções ambientais, as usinas destacaram a relevância da educação ambiental como um requisito nos projetos ambientais.

Dentre os projetos ambientais da empresa A estão: 
- Centro de Educação Ambiental: objetiva conscientizar estudantes, colaboradores e a comunidade sobre a importância da manutenção e do respeito ao meio ambiente;

- Projeto Viva a Natureza: recuperação e proteção de nascentes e mananciais, além de minimizar os riscos de assoreamento nos cursos d'água nas áreas que abrangem a usina através da recuperação de matas ciliares;

- Projeto Viveiro de Mudas: produz milhares de mudas de diversas espécies nativas para serem usadas nos projetos da própria empresa ou doadas a comunidades e governos locais;

- Concentração da vinhaça: projeto que concentra a vinhaça através de evaporadores, reduzindo o custo de transporte;

- Preservação do Solo: monitoramento e preservação das condições do solo, através de ações como o uso de mecanização na colheita, formulação da adubação em laboratórios para evitar desperdícios e controle biológico de pragas.

Já a usina $B$ também destacou projetos relacionados à educação ambiental, mas somente voltados para funcionários, além de contar com projetos de reciclagem e recuperação ambiental vistos nas seguintes práticas:

- Mutirão do lixo eletrônico: recebe e destina corretamente todo o lixo eletrônico gerado pela empresa e seus colaboradores;

- Educação Ambiental: enfatiza-se a problemática do ambiente rural, incentivando a adoção de posturas de conservação, de preservação e de interferência benéfica ao ambiente;

- Projeto Ambiental 3R (reduzir, reutilizar e reciclar): objetiva conscientizar os colaboradores através do conceito de que pequenas ações podem contribuir de forma positiva para o meio ambiente, tais como a substituição de copos descartáveis por canecas plásticas individuais;

- Levantamento da Flora e da Fauna: objetiva o levantamento da flora e da fauna visando checar se alguma espécie de planta ou animal está em risco de extinção; 
- Gerenciamento de resíduos diversos: resíduos como baterias, pneus, tambores, óleos e resíduo ambulatorial são destinados a empresas certificadas para receber esse tipo de material;

- Antecipação da cana queimada: uso de tecnologia para ter sua colheita totalmente mecanizada.

Ambas as usinas também possuem projetos de conservação de matas ciliares, de preservação de Áreas de Proteção Permanente (APP's) e de reflorestamento. No entanto, que estas se constituem em ações necessárias para o cumprimento de normas ambientais.

\subsubsection{Divulgação das práticas ambientais}

A empresa A divulga as ações ambientais para seus acionistas e investidores, funcionários, fornecedores, clientes e consumidores além da comunidade, autoridades públicas, associações de classe e organizações da sociedade civil relacionadas às atividades da companhia ou a seus impactos. Para alcançar esse público ela conta com a divulgação em outras línguas e os canais utilizados são intranet, internet, folders, palestras, visitas, semana de tecnologia e encontros. Nesta usina foi possível perceber grande preocupação em divulgar dados de desempenho ambiental para acionistas e foi também por esse objetivo que se desenvolveu o Relatório de Sustentabilidade de acordo com as diretrizes da Global Reporting Initiative (GRI), demonstrando indicadores do desempenho socioambiental da empresa.

$A$ usina $B$ realiza a divulgação para o mesmo público da empresa $A$, mas sem contar com a comunicação divulgada em outras línguas, além de ser mais restrita ao seu jornal organizacional interno e ao site da empresa. A usina também confeccionou o Relatório de Sustentabilidade (GRI) para demonstrar seu desempenho socioambiental através da exposição dos seus projetos.

As usinas demonstraram preocupação com a comunicação da importância dos seus projetos ambientais dentro dos seus limites, sobretudo por meio da conscientização dos funcionários. Para elas esta é uma questão que ocasiona 
mudanças na cultura organizacional através de novos valores e atitudes em todos os níveis funcionais.

\subsubsection{Balanço das práticas ambientais}

A Usina A avalia o desempenho de suas práticas e projetos de acordo com os resultados provenientes da sua política ambiental e SGA, vistos muitas vezes nos seus indicadores ambientais divulgados através do seu Relatório de Sustentabilidade. Para a empresa, o controle desses indicadores é muito importante para mensurar seu impacto no ambiente e identificar gargalos e melhorias em suas práticas e políticas. Esses indicadores abordam: materiais utilizados na cadeia produtiva; consumo de energia por fontes renováveis e não renováveis; emissões de gases do efeito estufa mediante ao inventário de emissões de Gases de Efeito Estufa (GEEs) no formato Protocolo GHG; descarte da água e suas destinações; disposição e quantidade gerada de resíduos; e conformidade com regulamentos ambientais. Desta forma, a usina A consiste em uma empresa organizada e com alto nível de controle ambiental demonstrado por seus indicadores.

Não foi possível identificar o mesmo nível de controle na usina $B$, cujas mensurações são focadas somente no volume das emissões de gases do efeito estufa, na demanda de água utilizada em seus processos industriais e na eficiência energética. Desta maneira, a usina B limita-se à percepção das melhorias ambientais mediante as consequências das práticas ambientais que realiza.

\subsubsection{Motivações e resultados dos investimentos ambientais}

Ambas as usinas mostraram interesse na ampliação da venda de açúcar e etanol no mercado externo, o qual faz exigências para práticas com maior qualidade e preocupação com o meio ambiente em suas operações. Desta forma, quanto às motivações para investimentos em questões ambientais nas suas estratégias e operações, a usina A enfatiza a abertura de mercado, a sustentabilidade do negócio e o incremento em credibilidade e lucratividade da empresa. Para a usina $B$, as 
motivações centraram-se na abertura de mercado proporcionada pela melhoria na imagem organizacional e pelo atendimento das exigências do mercado.

\subsection{Avaliação da adequação da destinação de resíduos e subprodutos}

É apresentada a seguir a discussão da adequação de cada uma das destinações dos resíduos e subprodutos praticadas pelas usinas estudadas.

\subsubsection{Efluente de lavagem de cana}

A usina A não realiza a lavagem da cana, não gerando, portanto, este efluente. Já a usina B realiza esta operação. Apesar disto, a empresa reutiliza o efluente gerado na própria planta industrial a partir de circuito fechado, o que se constitui em uma saída ambientalmente adequada para tal resíduo.

\subsubsection{Bagaço}

Com relação a este subproduto, ambas as empresas alegaram utilizá-lo completamente para a geração de energia elétrica (cogeração).

Esta postura mostra-se ambientalmente adequada, uma vez que o bagaço da cana é considerado uma fonte limpa de energia, pois o gás carbônico emitido na queima é recuperado pela fotossíntese do próprio cultivo da cana. Aqui há uma situação não conclusiva entre os cientistas. Apesar de haver na literatura afirmações de que as emissões de gás carbônico pela queima não deva ser contabilizada em virtude do ciclo renovável da biomassa, há autores que contestam esta hipótese, afirmando que esta soma não é zero, havendo maior volume de gás carbônico produzido do que capturado pela cana de açúcar. Por outro lado, há especialistas que consideram a fixação do referido gás pelos canaviais se dá em volume ainda maior do que a emissão pela combustão do bagaço, pois parte deste gás carbônico se transforma em açúcar e não em etanol e, desse modo, nem todo o gás carbônico retorna ao meio ambiente. 
Por outro lado, destaca-se que as usinas geram energia excedente que é exportada às distribuidoras de energia elétrica, significando uma geração complementar às hidrelétricas, alternativa importante nas épocas de seca.

\subsubsection{Cinzas da queima do bagaço}

As duas usinas pesquisadas dão a mesma destinação a este resíduo, ou seja, a partir de processo de compostagem é produzido um fertilizante sólido que, por sua vez, é utilizado no plantio de cana de açúcar realizado nas terras de propriedade das empresas.

Deste modo, nota-se a adequação ambiental desta postura já que a utilização deste resíduo possibilita alta capacidade de retenção de água no solo, reduzindo os impactos ambientais causados pela irrigação.

\subsubsection{Particulados gerados durante a queima do bagaço}

O material particulado gerado na queima do bagaço possui implicações ambientais relevantes caso emitido diretamente no ambiente, tais como problemas respiratórios na comunidade do entorno e sujidades nas localidades próximas às operações produtivas. Neste sentido, existem resoluções CONAMA que versam sobre as emissões máximas permitidas de particulados gerados neste processo.

Com relação às posturas adotadas pelas empresas pesquisadas relativas a este resíduo, tanto a usina $A$ quanto a $B$ alegaram seguir as resoluções que regem estas emissões adotando, assim, destinações ambientalmente adequadas.

\subsubsection{Gases da queima do bagaço}

As empresas pesquisadas declararam seguir as resoluções CONAMA pertinentes às emissões máximas dos gases $\mathrm{NO}_{x}$ e $\mathrm{CO}_{2}$ regulamentadas pelas normas. Porém, a queima do bagaço gera, além destes, outros gases de efeito estufa, tais como metano, monóxido de carbono e óxido nitroso, que acabam sendo liberados na atmosfera. 
Como efeito, pode-se afirmar que em ambas as empresas a destinação dada a este resíduo é inadequada.

\subsubsection{Efluente do tratamento dos gases de combustão da caldeira}

A usina A reutiliza a água deste efluente, após decantação, no próprio processo industrial (circuito fechado). Já a usina B adota outra postura, aplicando o efluente na lavoura a partir de sua incorporação à vinhaça.

Do ponto de vista ambiental, a utilização deste efluente em circuito fechado se mostra mais adequada uma vez que esta atitude reduz a necessidade de captação de água dos mananciais. Porém, a utilização na lavoura é também ambientalmente apropriada.

\subsubsection{Efluente de descarga das caldeiras}

As usinas utilizam este resíduo na fertirrigação, a partir de sua incorporação à vinhaça. Por se tratar de um efluente com baixa DBO, esta prática se mostra adequada do ponto de vista ambiental.

\subsubsection{Lodo proveniente da descarga das caldeiras}

A usina A alega não possuir este tipo de resíduo haja vista a utilização que esta empresa faz de uma tecnologia mais moderna que possibilita a não ocorrência do lodo. Já a empresa $B$ incorpora este material à torta de filtro e utiliza o produto para aplicação na lavoura, o que se constitui em uma atitude ambientalmente adequada.

\subsubsection{Torta de filtro}

A torta de filtro se constitui em um subproduto com elevada DBO, o que impossibilita sua descarga em corpos d'água sob a pena de alto impacto ambiental. Com relação a este material, ambas as empresas utilizam a torta de filtro para a 
aplicação na lavoura como incremento à fertilidade do solo pelo fornecimento de altos índices de matéria orgânica. Desta maneira, esta prática pode ser considerada adequada do ponto de vista ambiental.

\subsubsection{Efluente condensado dos evaporadores}

Com relação a este efluente, ambas as empresas adotam atitudes ambientalmente apropriadas. Por se tratar de um efluente límpido e quente, a usina A utiliza este efluente nas caldeiras, ou seja, no próprio processo produtivo. Por outro lado, a usina B o incorpora à vinhaça utilizada na fertirrigação.

\subsubsection{Efluente dos condensadores barométricos}

As práticas adotadas com relação a este efluente são ambientalmente adequadas nas duas usinas, apesar das empresas diferirem com relação ao destino dado ao referido resíduo. A usina $A$ utiliza o efluente no processo de destilação do etanol e a usina $B$ o utiliza na fertirrigação.

\subsubsection{Melaço}

Com relação a este subproduto, a usina A utiliza o melaço para a produção de etanol. Isto se deve ao fato do melaço conter substâncias como sacarose, glicose e frutose que permitem utilizá-lo para este fim. Esta é a prática mais comum nas usinas sucroenergéticas.

Por outro lado, a usina B não realiza esta operação de reaproveitamento, destinando o melaço à venda a terceiros. Ambas as destinações são consideradas ambientalmente adequadas.

\subsubsection{Efluente das emissões gasosas nas dornas de fermentação}

A etapa de fermentação da produção sucroenergética gera gás carbônico, produto de considerável valor comercial, utilizado para a produção de bebidas 
carbonatadas como refrigerantes, por exemplo. A despeito disto, as duas usinas investigadas não realizam a captura do referido gás nesta etapa, sendo este liberado no meio ambiente. Assim, pelo fato do gás carbônico se constituir em uma gás do efeito estufa, a destinação das empresas estudadas pode ser considerada ambientalmente inadequada.

\subsubsection{Levedura seca}

A usina A destina a levedura em excesso proveniente do processo de fermentação para aplicação na agricultura, em uma mistura com a vinhaça. Já a usina B comercializa a levedura em excesso. Ambas as atitudes são consideradas adequadas do ponto de vista ambiental.

\subsubsection{Vinhaça}

As duas usinas utilizam toda a vinhaça produzida durante o processamento da cana de açúcar na fertirrigação. Esta prática é preferível ao antigo exercício de lançamento em corpos d’água, cujos impactos ambientais são muito altos dada a alta carga de matéria orgânica deste material. Embora existam controvérsias sobre ser esta uma atitude anódina, para muitos especialistas esta é considerada uma prática ambientalmente adequada.

\subsubsection{6 Óleo fúsel}

A usina A possui uma atitude ambientalmente adequada com relação ao óleo fúsel gerado na produção, comercializando-o com empresas que o aproveitam como matéria-prima em diversos processos produtivos.

A usina B, no entanto, realiza o descarte do excesso deste subproduto juntamente com as águas residuárias, prática considerada inadequada do ponto de vista ambiental dadas às especificidades de sua composição e seu baixo pH. 


\subsubsection{Flegmaça}

A usina A reutiliza a flegmaça no próprio processo, sendo esta uma opção ambientalmente adequada e preferível, já que reduz a necessidade de captação de água por parte da empresa.

A usina $B$, por sua vez, agrega este resíduo à vinhaça e aplica o produto diretamente na lavoura, destinação também ambientalmente adequada.

\subsubsection{Etanol bruto}

Embora com destinações distintas dadas a este efluente, ambas as usinas possuem atitudes adequadas com relação a este resíduo. A usina $A$ o reincorpora ao processo de produção do etanol enquanto que a usina B o comercializa.

\subsubsection{Resíduos da desidratação do etanol hidratado}

As usinas investigadas possuem processos produtivos que não carecem da utilização as resinas zeolíticas na etapa de disidratação do etanol não gerando, portanto, tais resíduos.

\subsubsection{Efluente de lavagem de pisos e equipamentos}

As empresas em questão, após separação do óleo presente neste efluente, incorporam este resíduo à vinhaça, com consequente aplicação na lavoura (fertirrigação). Esta destinação é considerada ambientalmente adequada desde que a separação da porção oleica seja devidamente realizada.

\subsubsection{Efluente de lavagem das dornas}

Dentre as usinas, a empresa A realiza o processo de fermentação por fluxo contínuo, não gerando este tipo de efluente. Já a usina $B$, por empregar o processo 
de fermentação dito por batelada, possui a geração de tal resíduo que é incorporado à vinhaça na fertirrigação, destino este adequado ambientalmente.

\subsubsection{2 Óleos lubrificantes da fábrica}

Tanto a usina $A$ quanto a $B$ encaminham os resíduos desta natureza a empresas especializadas no refino deste material para posterior comercialização, prática esta considerada adequada.

\subsubsection{Sólidos decantados}

Os sólidos decantados nas lagoas de sedimentação tem por destino a lavoura em ambas as empresas, destinação ambientalmente adequada.

\section{CONSIDERAÇÕES FINAIS}

Tendo como pano de fundo a nova realidade empresarial, permeada de preocupações e fortes regulamentações ambientais, o presente estudo buscou apurar as práticas ambientais, tanto estratégicas quanto concernentes à destinação dada aos resíduos e subprodutos gerados no processo industrial, em duas usinas produtoras de açúcar, álcool e energia.

Nos últimos anos, o setor sucroenergético, tradicional alvo de críticas de cunho ambiental, conseguiu reverter esse cenário mediante fortes regulamentações e a um maior comprometimento com a realização de práticas ambientalmente adequadas. Assim, percebeu-se nesta pesquisa que as usinas estudadas demonstraram, a partir de suas ações, as transformações do ambiente em estudo e a nova realidade setorial.

Destaca-se que a motivação encontrada para a adoção de novas posturas com relação ao meio ambiente não é fruto somente de uma conscientização ambiental dos empresários ou do cumprimento das regulamentações deste âmbito. As empresas estudadas foram obrigadas a assumir novas atitudes também por pressão de clientes e fornecedores para produtos e processos mais sustentáveis. 
Portanto, a adoção das práticas ambientais por essas empresas também pode ser vista como uma estratégia de mercado para a abertura de novos negócios e para obtenção de maior credibilidade, advindas com a melhoria da imagem organizacional.

Com relação às práticas de cunho estratégico, ambas as usinas pesquisadas possuem Sistemas de Gestão Ambiental formalizados, mas utilizam-se de distintos processos sustentáveis que variam de acordo com a estratégia gerencial e recursos disponíveis. Portanto, foi visto que, apesar de estarem inseridas em condições setoriais similares, ambas adotam diferentes estratégias empresariais com práticas ambientais muitas vezes distintas ou abordadas de maneiras diferentes dentro da organização.

Com relação aos Sistemas de Gestão Ambiental adotados, foi visto que, apesar das certificações ambientais possíveis para o setor sucroenergético, as usinas estudadas possuem poucas certificações, especialmente a usina $B$, que formalizou suas práticas e estratégias ambientais somente mediante ao chamado Protocolo Agroambiental. Já a usina A mostrou maior preocupação nesse quesito, pois atestou suas práticas em certas certificações, algumas até sendo requisitos para exportação países como os Estados Unidos e União Europeia.

Por outro lado, as empresas analisadas demonstraram forte preocupação com a educação ambiental para os funcionários como medida estratégica e com a divulgação de suas práticas ambientais para os meios interno e externo. Porém, a divulgação utilizada pela usina $A$ se mostrou mais ampla e completa, destinada principalmente aos seus acionistas. Por meio dessa ação foi possível observar que seus indicadores de desempenho ambiental são também mais amplos face à usina B.

Com relação à adequação da destinação dada aos resíduos e subprodutos gerados durante as etapas industriais, a pesquisa realizada revelou que a maior parte das práticas adotadas pelas empresas mostram-se ajustadas do ponto de vista ambiental, uma vez que a maioria dos resíduos gerados é reaproveitada ou reincorporada aos processos das empresas, sobretudo com sua utilização na lavoura como componentes para a adubação ou para a chamada fertirrigação de 
solos destinados à produção da cana de açúcar, matéria prima principal desta indústria.

Porém, ambas as empresas possuem posturas inadequadas com relação à destinação dada aos gases da queima do bagaço e ao efluente das emissões gasosas nas dornas de fermentação e a usina $\mathrm{B}$, ainda, possui inconformidade com relação à destinação dada ao óleo fúsel gerado no processo produtivo, descartandoo juntamente com as águas residuárias, atitude esta ambientalmente questionável.

Neste sentido, apesar de muitas práticas adotadas pelas empresas pesquisadas serem análogas, é possível concluir que a usina A possui desempenho ambiental diferenciado com relação à usina $\mathrm{B}$, dada à maior atenção dispensada à execução de suas práticas ambientais, sobretudo na inclusão da variável ambiental em suas estratégias.

\section{AGRADECIMENTO}

Os autores agradecem à Fundação de Amparo à Pesquisa do Estado de São Paulo (FAPESP) pelo apoio financeiro à pesquisa.

\section{REFERÊNCIAS}

ARAÚJO, R. M. S. Análise da gestão ambiental em empresas agroindustriais de usinas de açúcar e álcool no Mato Grosso do Sul. Dissertação (Mestrado em Administração), Escola de Administração, UFRGS. Porto Alegre, 2001.

ASSOCIAÇÃO BRASILEIRA DE NORMAS TÉCNICAS (ABNT). ABNT NBR ISO 14001: requisitos com orientações para uso. Rio de Janeiro: 2004. 2.ed.

BARBIERI, J. C. Gestão ambiental empresarial: conceitos, modelos e instrumento. São Paulo: Saraiva, 2007. 2.ed.

CAGNIN, C. H. Fatores relevantes na implantação de um Sistema de Gestão Ambiental com base na norma ISO 14001. Dissertação (Mestrado em Engenharia de Produção), UFRGS. Porto Alegre, 2000.

CAMPOS, L. M. S.; MELO, D. A. Indicadores de desempenho do Sistema de Gestão Ambiental (SGA): uma pesquisa teórica. Revista Produção, v. 18, n. 3, pp. 540-555, 2008. 
DIAS, R. Gestão ambiental: responsabilidade social e sustentabilidade. São Paulo: Atlas, 2006.

DORNAIRE, D. Gestão ambiental na empresa. São Paulo: Atlas, 1999. 2. ed.

FERRAZ, J. M. G. Painel 4: gestão Ambiental. In: WORKSHOP DE PESQUISA SOBRE SUSTENTABILIDADE DO ETANOL. Anais.... São Paulo: APTA, 2007.

FIPA. Boletim Informativo da federação das Indústrias Portuguesas

Agroalimentares. 2007. Disponível em http://www.fipa.pt/pdf/fipaflash95.pdf> acessado em outubro de 2013.

HUNT, C. B.; AUSTER, E. R. Proactive environmental management: avoiding the toxic trap. Sloan Management Review. EUA: Putnam, Hayes \& Bartlett, Winter 1990.

MAIMON, D. Passaporte verde: gestão ambiental e competitividade. Rio de Janeiro: Qualitymark, 1996.

OLIVEIRA, S. M.; HANSEN, A. O.; SILVA, T. N.; PEDROZO, E. A.; BOLDIN, V. P. Responsabilidade sócio-ambiental no setor sucroalcooleiro: um estudo de caso na Pioneiros Bioenergia S/A. Revista Eletrônica de Gestão, v. 2, n. 1, pp. 111-134, 2009.

PIACENTE, F. J. Agroindústria canavieira e o sistema de gestão ambiental: o caso das usinas localizadas nas Bacias Hidrográficas dos rios Piracicaba, Capivari e Jundiaí. Dissertação (Mestrado) - IC-UNICAMP. Campinas: Unicamp, 2005.

REBELATO, M. G.; MADALENO, L. L.; RODRIGUES, A. M. Um estudo sobre a aplicabilidade do Just-in-Time na produção do etanol. Revista Produção Online, v. 12, n. 3, pp. 703-728, 2012. http://dx.doi.org/10.14488/1676-1901.v12i3.967

RODRIGUES, A. M.; PAIXÃO, R. B. S.; REBELATO, M. G. Análise de práticas ambientais: um estudo comparativo em duas usinas sucroalcooleiras. In: Anais do XXXIII Encontro Nacional de Engenharia de Produção (ENEGEP). Salvador: ABEPRO, 2013.

ROSSETTO, R. A cana de açúcar e a questão ambiental. In: DINARDO-MIRANDA, L. L.; VASCONCELOS, A. C. M.; LANDELL, M. G. A. Cana de açúcar. Campinas: Instituto Agronômico, 2008.

SANCHES, C. S. Gestão ambiental proativa. Revista de Administração de Empresas, v. 40, n. 1, pp. 76-87, 2000.http://dx.doi.org/10.1590/S0034$\underline{75902000000100009}$

ZEVIANI, C. H; RODRIGUES, A. M.; REBELATO, M. G. Elaboração de um roteiro de pesquisa para avaliação do desempenho ambiental em empresas industriais. In: 
Anais do XXXIII Encontro Nacional de Engenharia de Produção (ENEGEP). Salvador: ABEPRO, 2013.

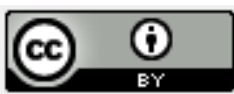

Artigo recebido em 17/12/2013 e aceito para publicação em 15/04/2014 DOI: http://dx.doi.org/ 10.14488/1676-1901.v14i4.1717 